\section{ESSENTIALS OF ORTHOPAEDICS}

By Philip Wiles, M.S.(Lond.), F.R.C.S.(ENg.), F.A.C.S. London: J. \& A. Churchill, 1949. Pp. xv and 486 with 7 colour plates and 365 illustrations. Price 42s.

For some years now both undergraduates and post graduates have continued to clamour for a reliable textbook on the essentials of orthopaedics. Mr. Wiles, from his position in charge of the Orthopaedic Department of one of the teaching hospitals is well aware of the needs of students, post graduates and general practitioners in their study of this branch of surgery. He pays grateful acknowledgment to the helpful criticism and advice which he has received from many of his colleagues on the staffs of other teaching hospitals, so we can assume that his book will contain all that its title suggests.

The book falls into three parts. A description of posture and postural deformity; a systematic consideration of affections of individual joints; and finally chapters on pyogenic infection, tuberculosis, chronic arthritis, tumours of bone, diseases and congenital deformities of bone, and diseases of the nervous system. This sort of arrangement is an excellent one, but it is open to argument that the more general description of diseases should have preceded the particular consideration of joints. Back pain he considers quite rightly as a subject of its own.

Starting with general remarks on posture, the author throws a new light on flat feet-'Pes Valgus,' as he would have us call that popular deformity. Rightly, he is caustic about the use of foot supports as a corrective measure, though he does not give them their full value as a practical means of bringing comfort to the many worn-out old travesties of feet which haunt our clinics.

In dealing with the spine, he helps the student to see the problem of low backache in a reasonable light, not overstressing disc protrusions, though sitting on a guarded fence when talking of ' myofascial pain.' He does not mention the value of the plaster jacket in the relief of disc lesions.

In his chapter on the hip he is most pleasantly clear about those conditions which give students nightmares at examination time. Perhaps his section on the knee is not quite so clear and does not make the diagnosis of 'internal derangements' more easy. He does not sufficiently stress the importance of re-education and exercise of the quadriceps muscle in treatment.
In the foot he emphasises most rightly the importance of great care in selection and execution of operations for hallux valgus.

That difficult matter of movement at the shoulderhe makes more easy to understand than any wor yet, and follows Codman's views on the relation of supraspinatus lesions to the sub-acromial bursa He does not mention 'peri-arthritis' as a clinica entity. Does he regard it only as the last resort of puzzled diagnosticians, or simply the extreme of sub-acromial bursitis ?

Osteomyelitis he clears up well, bringing it up to date with penicillin therapy. Bone tumours he makes easy with a simple classification and sound advice on treatment.

It may be suggested in criticism that a book on the essentials of orthopaedics should contain specias sections which describe in a general manner sucl things as the causation and treatment of all deford mities; manipulative treatment; splints and appliances; and the use of physical methods ing treatment, especially muscle training and exercise

No reviewer could fail to congratulate. Wiles anop his publishers, Messrs. J. \& A. Churchill Ltd., on! producing a volume of such excellent shape, style and quality, both in printing and illustration.

W.D.C.

\section{PSYCHOLOGICAL MEDICINE}

\section{( $A$ short introduction to psychiatry)}

By Desmond Curran, M.B., F.R.C.P., D.P.M. and the late ERIC GutrmanN, M.D., M.R.C. Foreword by Sir JoHN J. ConYBEARE, M.C. D.M., F.R.C.P. Third edition. Edinburgh E. \& S. Livingstone, 1949. Pp. 252. Pricê I2s. $6 \mathrm{~d}$.

The usefulness of this book can be seen from the fact that it has reached its third edition since 1942 ? each being in turn reprinted. With its precision and clear definitions this book is the best introduc tion a student can wish for. It shows the existence. of problems and avoids confusing the beginner without over-simplifying every issue. The appen 3 dix on war-time psychiatry contains the essentials: that one would wish every serving medical officer to know. It is hoped that the next edition will in corporate the relevant alterations and provisions of the law by the National Health Service Act and the Criminal Justice Act. 